\title{
2.5D Simulation of basin-edge effects on the ground motion characteristics
}

\author{
J P NARAYAN \\ Department of Earthquake Engineering, Indian Institute of Technology, Roorkee 247 667, India.
}

\begin{abstract}
The effects of basin-edge and soil velocity on the ground motion characteristics have been simulated using 2.5D modeling. One of the most significant advantages of the $2.5 \mathrm{D}$ simulation is that $3 \mathrm{D}$ radiation pattern can be generated in a $2 \mathrm{D}$ numerical grid using double-couple shear dislocation source. Further, 2.5D numerical modeling avoids the extensive computational cost of 3D modeling. The responses of basin-edge model using different soil velocities revealed that surface waves were generated near the edge of the basin and propagated normal to the edge, towards the basin. Further, the results depict increase of amplification, duration and surface wave generation with the decrease in soil velocity.
\end{abstract}

\section{Introduction}

In sedimentary basins, the locally generated surface waves play an important role on the damage distribution during earthquakes. A common conclusion was drawn in many studies by examining the phase and group velocities, polarity and arrival azimuth (estimated from the later arrivals) that later arrivals are primarily composed of surface waves generated at the basin-edge (Hatayama et al 1995; Kawase 1996). The high frequency surface waves generated at the basin-edge have been of great interest in the field of engineering seismology, since the 1985 Michoacan, Mexico earthquake. The Hyogo-ken Nanbu earthquake of 1995 and the 1994 Northridge earthquake are recent reminders that soft sediments and the basin-edge gave the most significant effects on surface wave generation and ground motion amplification.

The configuration for $2.5 \mathrm{D}$ wave simulation is achieved when the medium properties vary only in two dimensions and remain constant in the third direction, and the source-receivers are confined in the same plane. Narayan $(1998,1999)$ reported that the computational time for $2.5 \mathrm{D}$ models is only $12-15 \%$ more than that required for $2 \mathrm{D}$ models. Takenaka and Kennett (1996) developed
2.5D time domain elastodynamic wave equation. Narayan (2001) inferred that the $3 \mathrm{D}$ and $2.5 \mathrm{D}$ radiation patterns using a double-couple source, corroborate with each other in the $x z$-plane (figure 1 ). Narayan (2001) also reported that site-specific ground motion can be predicted just by rotating the strike of the fault in the anti-clockwise direction by the same amount as the azimuth of the site with respect to the epicenter. This adjustment is necessary since $2.5 \mathrm{D}$ response can only be computed in the $x z$-plane, with the $x$-axis pointing towards the north direction and the epicenter, focus and the desired site, all being coplanar to this.

\section{Methodology}

An algorithm developed by Narayan (2001), based on parsimonious staggered grid finite difference approximation (Ohminato and Chouet 1997) of Takenaka and Kennett's (1996) 2.5D elastodynamic wave equation, was used in the simulations. The source implementation into the computational grid was based on the moment tensor source formulation (Pitarka 1999; Narayan 2001). The second derivative of convolution of a polynomial window $\left[\left\{1-(\tau-1)^{2}\right\}^{3}\right]$ and the Gaussian function

Keywords. 2.5D simulation; radiation pattern; basin-edge effects; ground motion prediction. 


\section{Dip $=45$, Rake $=90$ \& Azimuth $=90$}

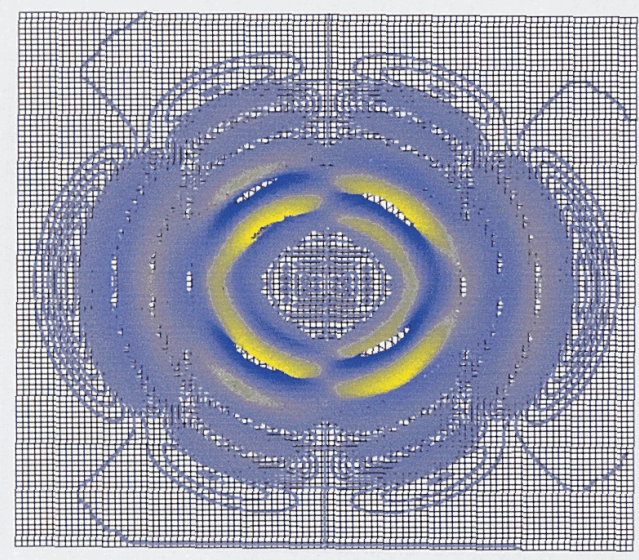

3D: Radial-XZ plane

(a)

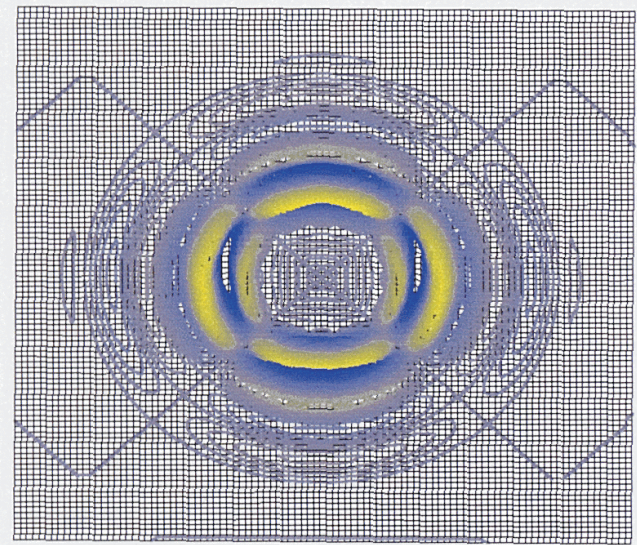

3D: Transverse-XZ plane

(b)

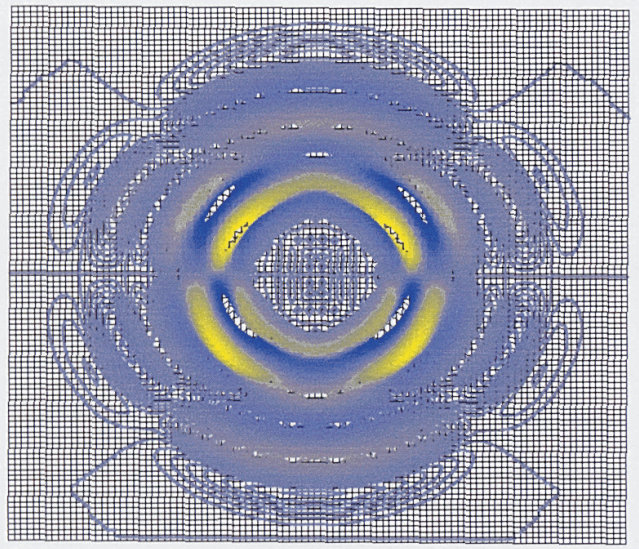

3D: Vertical-XZ plane

(c)

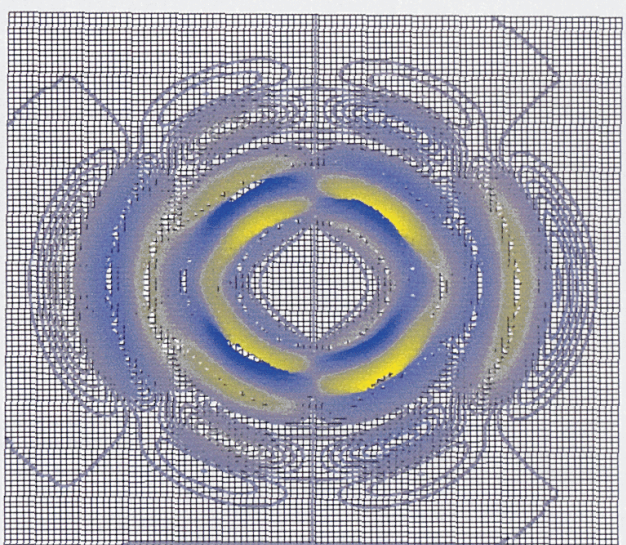

2.5D: Radial-XZ plane

(d)

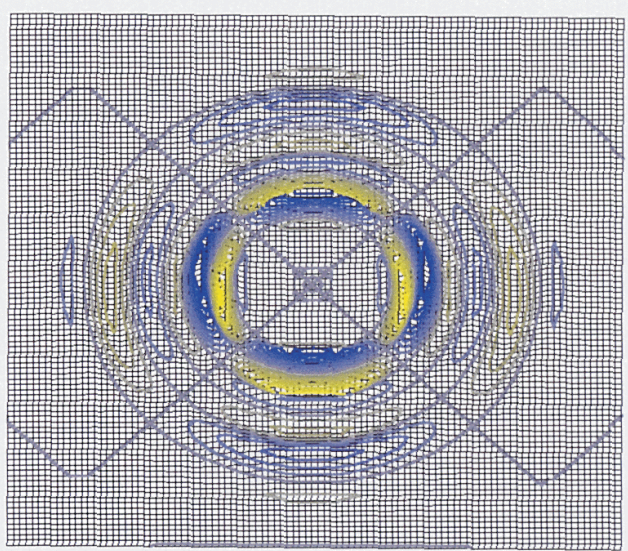

2.5D: Transverse- $X Z$ plane

(e)

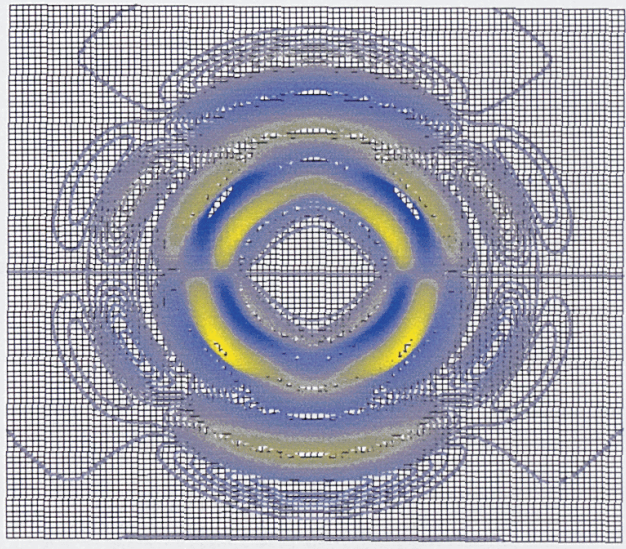

2.5D: Vertical-XZ plane

(f)

Figure 1. 3-D and 2.5-D radial, transverse and vertical components of the radiation for a point source with a focal mechanism of $\operatorname{dip}=45.0^{\circ}$, rake $=90.0^{\circ}$ and strike $=90.0^{\circ}$ (after Narayan 2001). 
Table 1. Different types of soils and their parameters used in the simulations.

\begin{tabular}{lrrrccc}
\hline $\begin{array}{c}\text { Type of } \\
\text { soil }\end{array}$ & $\begin{array}{c}V_{s} \\
(\mathrm{~m} / \mathrm{s})\end{array}$ & $\begin{array}{c}V_{p} \\
(\mathrm{~m} / \mathrm{s})\end{array}$ & $\begin{array}{c}\text { Density } \\
(\mathrm{g} / \mathrm{cc})\end{array}$ & $\begin{array}{c}\text { Poisson's } \\
\text { ratio }\end{array}$ & $\begin{array}{c}\text { Thickness } \\
\text { of soil }(\mathrm{m})\end{array}$ & $\begin{array}{c}\text { Fundamental } \\
\text { frequency }(\mathrm{Hz})\end{array}$ \\
\hline Soil 'A' & 400.00 & 1800.00 & 1.90 & 0.474 & 140.00 & 0.714 \\
Soil 'B' & 500.00 & 1900.00 & 1.95 & 0.462 & 140.00 & 0.892 \\
Soil 'C' & 600.00 & 2000.00 & 1.95 & 0.450 & 140.00 & 1.071 \\
Soil 'D' & 700.00 & 2100.00 & 2.10 & 0.437 & 140.00 & 1.250 \\
Soil 'E' & 850.00 & 2200.00 & 2.15 & 0.412 & 140.00 & 1.517 \\
Soil 'F' & 1250.00 & 2643.00 & 2.50 & 0.355 & 140.00 & 2.232 \\
Rock & 2000.00 & 3464.10 & 2.50 & 0.250 & - & - \\
\hline
\end{tabular}

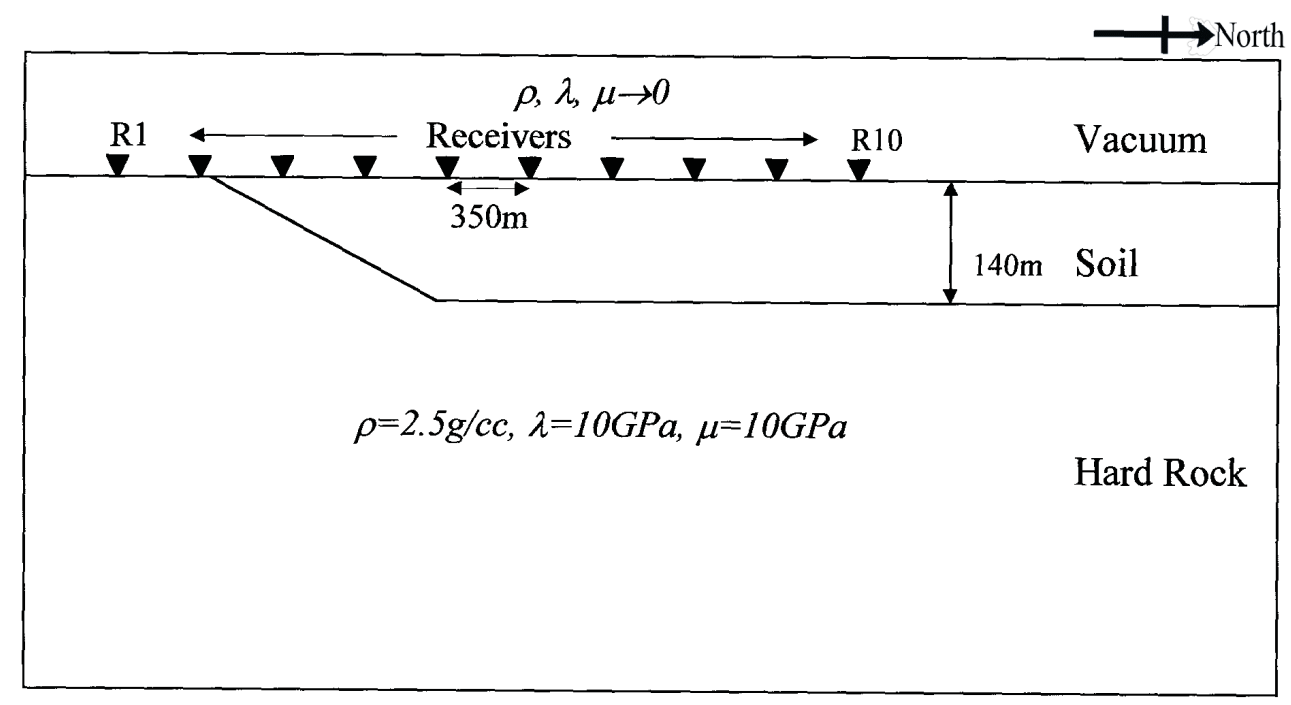

(a)

Figure 2. Vertically exaggerated basin-edge model and different receiver points.

$\left[\exp \left\{-\alpha\left(t-t_{0}\right)^{2}\right\}\right]$ was used as an excitation function (where $t_{0}$ is the time delay to the center point of the filter, $t$ is the duration of filter, $\tau=t / t_{0}$ and $\left.\alpha=\left(\pi / t_{0}\right)^{2}\right)$. In the present study, vacuum formulation was adopted in which Lame's parameters $\lambda$ $\& \mu$ and density $\rho \rightarrow 0$ in the region above the free surface (Graves 1996; Narayan 2001).

\section{Simulation of basin-edge model}

A two layered basin-edge model was simulated for six types of soils (Soil 'A' to 'F', table 1), to study the effects of basin-edge and soil velocity on the ground motion characteristics. Figure 2 shows the north-south cross section of the model and its southern edge. The northern basin-edge is assumed to be far away. Ten-equidistant $(350 \mathrm{~m})$ receivers (R1-R10) were used for recording. The $P$ - and $S$ waves velocities, densities, Poisson's ratios and fundamental frequencies of different soils in the upper layer and half space (hard rock) are given in table 1.
In the simulation, the positive $x$-coordinate points in the north direction. The model $(17.5 \mathrm{~km}$ $\times 16.5 \mathrm{~km}$ ) was descretised into square grids of $35 \mathrm{~m}$ size. The width of the sponge boundaries (Israeli and Orszag 1981) on the left, right and lower sides of the model was $0.52 \mathrm{~km}$ and the thickness of the vacuum created over the model was $0.17 \mathrm{~km}$. The time step and dominant frequency were taken as $0.004 \mathrm{~s}$ and $1.0 \mathrm{~Hz}$, respectively. The source with focal mechanism of dip $=45.0^{\circ}$, rake $=$ $90.0^{\circ}$ and strike $=60.0^{\circ}$ was generated $1.155 \mathrm{~km}$ south of the edge of the basin at a depth of $14.0 \mathrm{~km}$. Figures $3(\mathrm{a}-\mathrm{f})$ show the variations of ground displacement in the radial component at different receivers for soil 'A' to soil ' $F$ ', respectively. The basin-edge has caused strong generation of surface waves, which were recorded just after the arrivals of the incoming $S$-waves. These surface waves were identified based on very large coherence among the recording stations. It is clear from the responses that surface waves were generated near the basinedge and propagated normal to it, towards the basin. Increase of the time gap between the incom- 

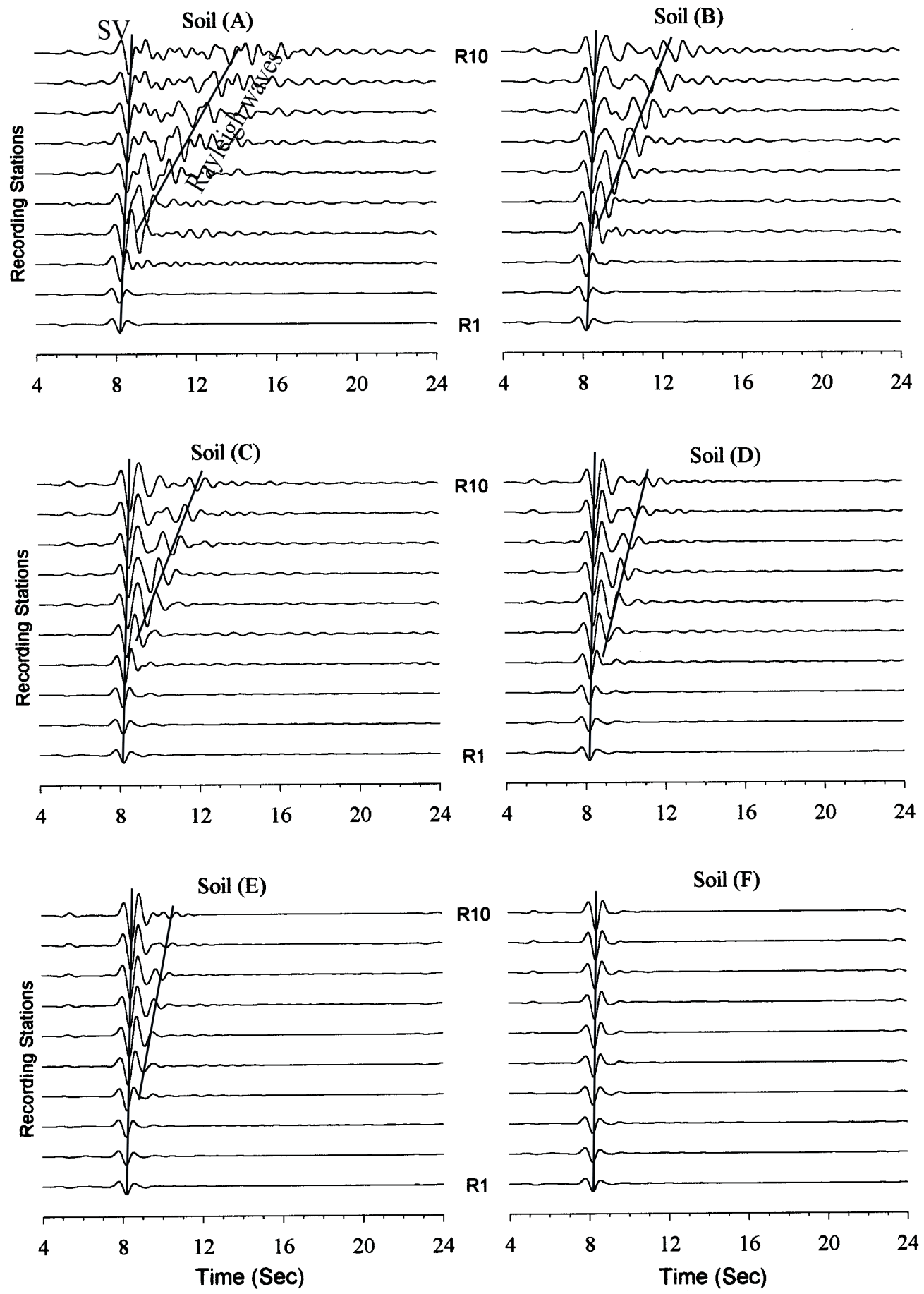

Figure 3. Radial component of the responses of the basin-edge model with different soils.

ing $S$-waves and the corresponding surface waves, as we go away from the basin-edge confirms the above conclusion.

Furthermore, this conclusion gets support from the decrease of time separation between the $S$ waves and the corresponding surface waves with the increase of soil velocity in the basin. The analysis of figure 3 reveals that in the radial component the amplitude of incoming waves almost continuo- usly increases with decrease of soil velocity in the basin. There is tremendous increase of surface wave amplitude and duration with decrease in the soil velocity. Very large amplitude at stations R4 and R5 may be due to constructive interference. Similar effects on surface wave generation and amplitude amplification in the transverse (figure 4) and vertical components (figure 5) can be observed. Smaller amplitude in the transverse component as 

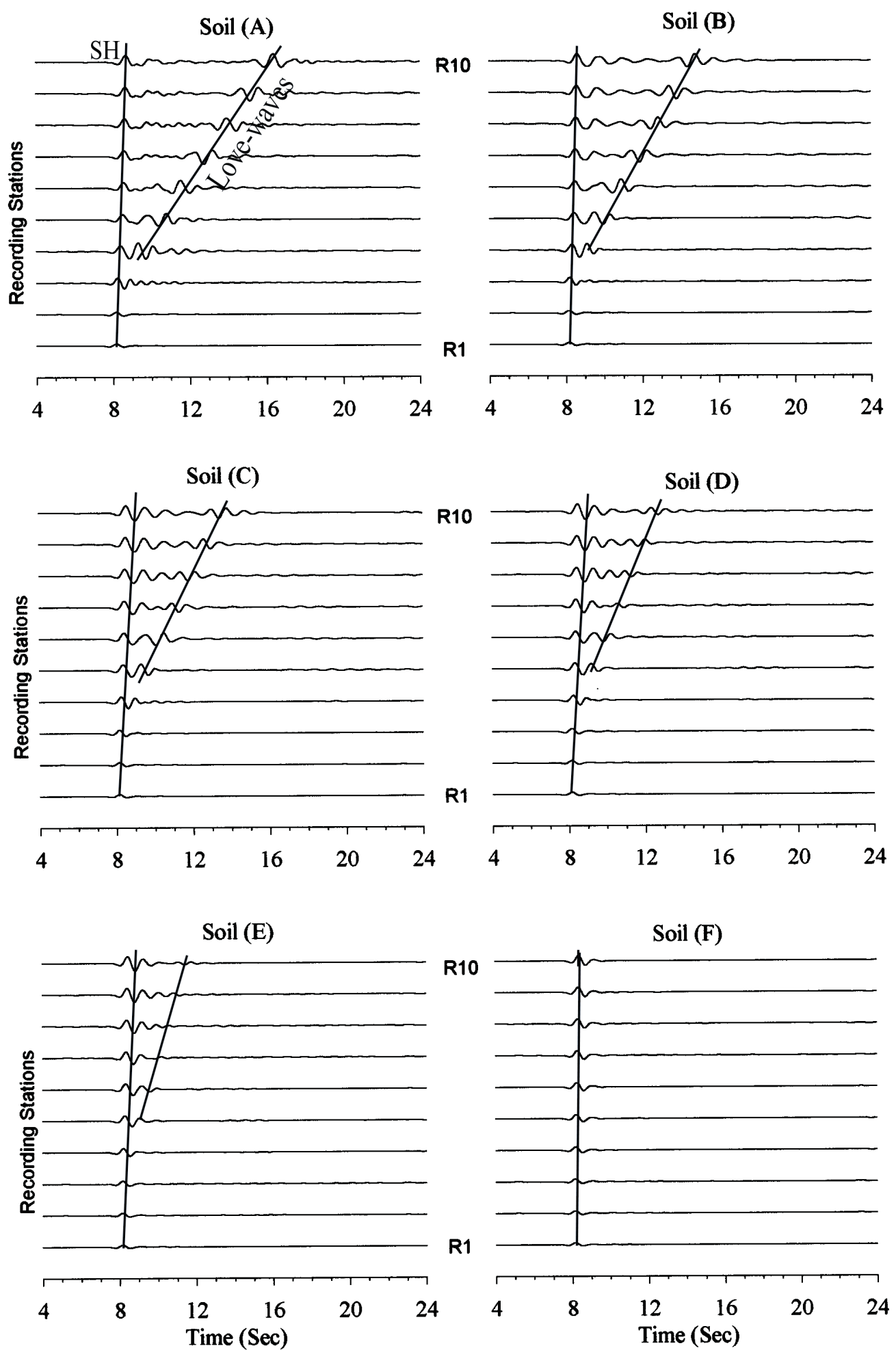

Figure 4. Transverse component of the responses of the basin-edge model with different soils.

compared to the other two components is due to the source effect. In the vertical component (figure 5) the amplitudes of surface waves are very large as compared to the incoming waves. Surface waves are highly dispersive in the radial and vertical components as compared to the transverse component.

\section{Conclusions}

An algorithm developed by Narayan (2001) using Takenaka and Kennett's (1996) 2.5D elastodynamic wave equation was used for the study of effects of basin-edge on the ground motion characteristics. The 2.5D modeling has simplified the 

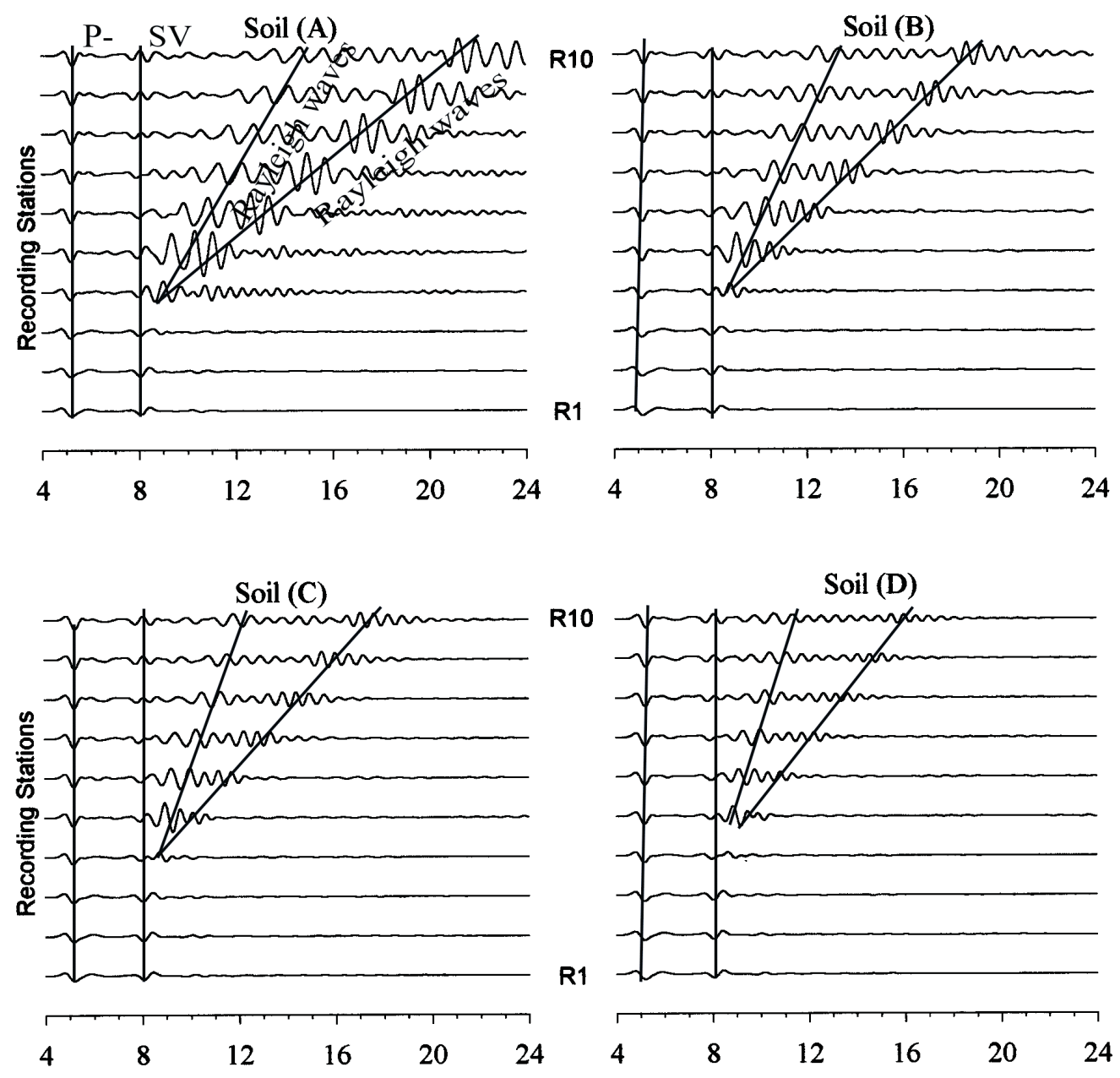

Soil (E)
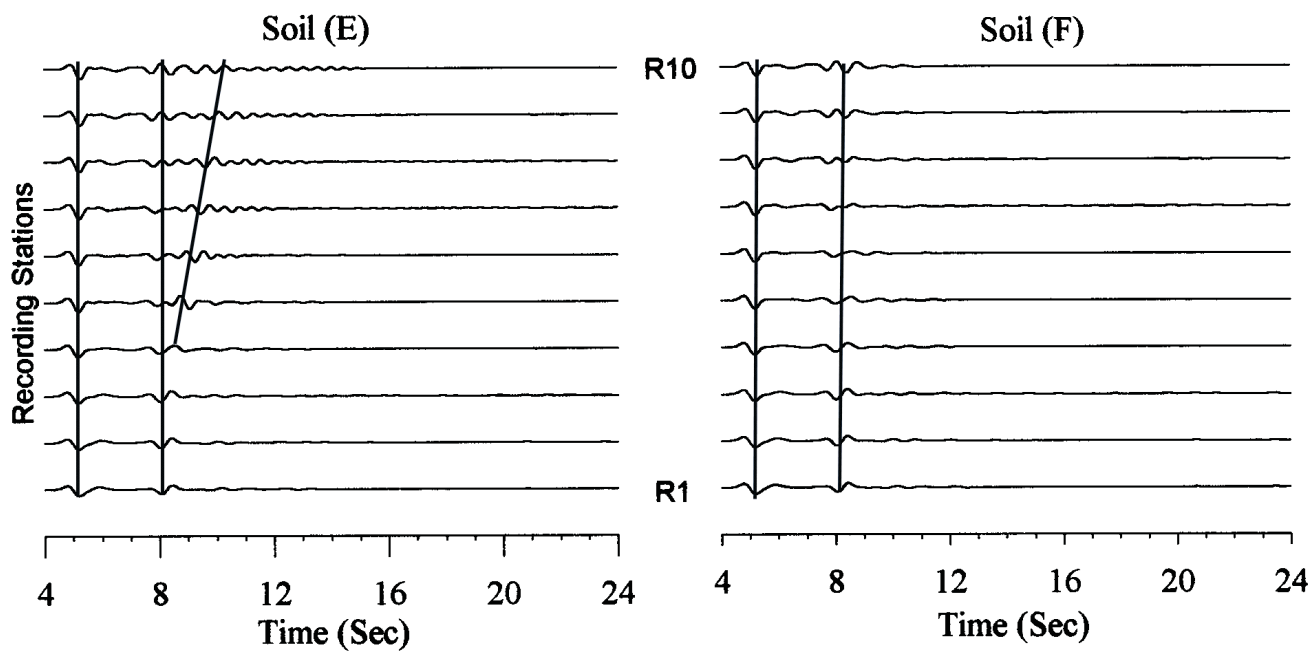

Figure 5. Vertical component of the responses of the basin-edge model with different soils.

procedure for simulating the 3D seismic responses by implementing a double-couple shear dislocation source into the numerical grid. The analysis of responses of basin-edge model reveals that surface waves were generated near the edge of the basin and propagated towards the basin (Hatayama et al
1995 and Kawase 1996). The increase of time separation between the incoming $S$-waves and the corresponding surface waves as we go towards the basin, supports the conclusion that surface waves were generated near the edge of the basin. This conclusion gets further support by decrease of time 
separation between the incoming $S$-waves and the corresponding surfaces waves with the increase of soil velocity in the basin.

Results also reveal that within the basin itself, surface waves were either not generated or their amplitudes are very small. The large ground motion amplitude near the basin-edge may be due to the constructive interference of diffracted waves/surface waves with direct waves (Kawase 1996). The amplitudes of surface waves in the radial and vertical components were even more than those of incoming waves. The surface waves in the radial and vertical components are more dispersive as compared to the transverse component. Simulated results revealed that edge effects in the sedimentary basin deserve a particular attention for earthquake resistant design, seismic microzonation, and damage and loss scenarios.

\section{Acknowledgements}

Financial assistance by the Indian National Science Academy (INSA), New Delhi is gratefully acknowledged.

\section{References}

Graves R W 1996 Simulating seismic wave propagation in 3D elastic media using staggered grid finite difference; Bull. Seism. Soc. Am. 86 1091-1106

Hatayama K K, Matsunami T Iwata and Irikura K 1995 Basin-induced love waves in the eastern part of the Osaka basin; J. Phys. Earth 43 131-155

Israeli M and Orszag S A 1981 Approximation of radiation boundary conditions; J. Comp. Phys. 41 115-135

Kawase H 1996 The cause of damage belt in Kobe: "The basin-edge effect", constructive interference of the direct $S$-waves with the basin induced diffracted/Rayleigh waves; Seism. Res. Lett. 67 25-34

Narayan J P 1998 2.5D numerical simulation of acoustic wave propagation; Pure and Appl. Geophys. 151 47-61

Narayan J P 1999 2.5-dimensional cross-hole acoustic response: a variable density approach; Geophys. J. Int. $139879-887$

Narayan J P 2001 Site specific strong ground motion prediction using 2.5D modeling; Geophys. J. Int. 146 269-281

Ohminato T and Chouet B A 1997 A free surface boundary condition for including 3D topography in the finite difference method; Bull. Seism. Soc. Am. 87 494-515

Pitarka A 1999 3D elastic finite difference modeling of seismic motion using staggered grids with nonuniform spacing; Bull. Seism. Soc. Am. 89 54-68

Takenaka H and Kennett B L N 1996 A 2.5D time domain elasto-dynamic equation for plane wave incidence; Geophys. J. Int. 125 F5-F9 